\title{
A comparison of the cytoplasmic domains of the Fas receptor and the p75 neurotrophin receptor
}

\author{
H Kong $^{1,2}$, AH Kim ${ }^{1,2}$, JR Orlinick ${ }^{1}$ and MV Chao*,1 \\ ${ }^{1}$ Molecular Neurobiology Program, Skirball Institute, New York University \\ Medical Center, 540 First Avenue, New York, NY 10016, USA \\ 2 The first two authors contributed equally to this study \\ * Corresponding author: MV Chao, Molecular Neurobiology Program, Skirball \\ Institute, New York University Medical Center, 540 First Avenue, New York, NY \\ 10016, USA. Tel: +1 212-263-0722; Fax: +1 212-263-0723; \\ E-mail: chao@saturn.med.nyu.edu
}

Received 15.7.98; revised 20.8.99; accepted 23.8.99

Edited by $\mathrm{C}$ Thiele

\begin{abstract}
The p75 neurotrophic receptor (p75) shares structural features with the Fas receptor (FasR). Both receptors contain extracellular cysteine-rich repeats, a single transmembrane domain, and intracellular death domains. However, it has not been clearly established whether their death domains are equivalent in their ability to mediate apoptosis. To understand better the role of p75 during apoptosis, we constructed chimeric receptors that contained the extracellular portion of the FasR and the intracellular portion of $p 75$. These chimeric receptors, one containing the $p 75$ transmembrane domain and the other containing the FasR transmembrane portion, as well as wild-type p75 and Fas receptors, were transiently transfected into human U373 glioma cells and human embryonic kidney 293 cells (293 cells), which are both responsive to Fas-mediated apoptosis. Whereas expression of FasR was sufficient to induce apoptosis in U373 and 293 cells, expression of $\mathrm{p} 75$ and the chimeric receptors induced only minimal levels of cell death compared to FasR. The results indicate that the magnitudes of FasR-and p75-induced killing are different and suggest that the death domain of $p 75$ does not function in the same manner as the FasR death domain.
\end{abstract}

Keywords: neurotrophins; p75 receptor; death domain; Fas receptor

Abbreviations: DRG, dorsal root ganglion; FADD, Fas-associated death domain protein; FLICE, FADD-like ICE; FasR, Fas receptor; GFP, green fluorescent protein; JNK, c-jun kinase; LIF, leukemia inhibitory factor; MACH, MORT1-associated CED-3 homolog; MORT, mediator of receptor-induced toxicity; NGF, nerve growth factor; NTR, neurotrophin; PE, phycoerythrin; TNF, tumor necrosis factor; TRAF, TNF receptor associated factor; TRADD, TNF-R1associated death domain protein; TUNEL, TdT-mediated dUTP Nick End Labeling

\section{Introduction}

The p75 receptor is the founding member of the TNF receptor superfamily. ${ }^{1}$ Structural features shared by several members of this family include a cysteine-rich extracellular domain repeated two to six times and an intracellular motif termed the 'death domain'. The term 'death domain' was coined from its functional role in mediating apoptosis, particularly via the p55 TNF receptor and FasR. ${ }^{2,3}$ The death domain is a protein association motif ${ }^{4,5}$ that binds to cytoplasmic proteins, which can trigger the caspase protease cascade or other signal transduction pathways. Multiple adaptor and death effector proteins that bind to the death domains of the p55 TNF and Fas receptors have been identified.

Considerable attention has been focused upon the possibility that p75 acts as a cell death receptor. ${ }^{6-10}$ Apoptosis has been detected in p75-positive retinal precursor cells during embryonic development ${ }^{11,12}$ and in transgenic mice overexpressing the cytoplasmic domain of p75. ${ }^{13}$ In differentiated oligodendroglial cells in vitro, nerve growth factor (NGF), a ligand for $\mathrm{p75}$, induces a rapid apoptotic response. ${ }^{14} \mathrm{~A}$ cell death role for $\mathrm{p} 75$ has been implicated in several p75-expressing cell lines ${ }^{15,16}$ and also in sensory ${ }^{17}$ and sympathetic neurons. ${ }^{18}$ Following nerve injury and other traumatic conditions, p75 is frequently found to be upregulated in a variety of different cell types. In fact, apoptosis, of Schwann cells ${ }^{19}$ and neuronal cells after seizure ${ }^{20}$ have been correlated with high levels of p75 receptor expression.

Despite evidence that p75 participates in apoptosis, the mechanisms responsible for this activity remain undefined. Elucidation of the actions of p75 is complicated by the expression of Trk receptor tyrosine kinases, which exert a prominent survival or proliferative signal. The TrkA, TrkB, and TrkC tyrosine kinases are receptors for NGF, BDNF and NT-4, and NT-3, respectively. ${ }^{21}$ The p75 receptor serves as a receptor for all of the neurotrophins and can enhance Trk signaling functions. ${ }^{22-24}$ Additionally, activation of TrkA prevents p75-mediated apoptosis when both receptors are co-expressed. ${ }^{25}$

The existence of a death domain sequence at the Cterminus of $p 75^{26}$ suggests that p75-mediated apoptosis may be mechanistically similar to Fas and the p55 TNF receptors. Given the structural homology between p75 and the other TNF receptor family members, it is conceivable that p75 may initiate apoptosis through a mechanism involving receptor oligomerization and recruitment of cell death proteins. In this study, we have tested whether p75 acts like the FasR by generating chimeric receptors with $\mathrm{p} 75$ and FasR and assessed the functional consequences of their expression in cultured cells. 


\section{Results}

The nuclear magnetic resonance (NMR) structures of the cytoplasmic domains of both FasR and p75 have been reported. ${ }^{26,27}$ The death domains of both proteins are composed of six alpha helices which form a globular structure. Given this overall structural similarity, we were interested in determining whether the death domain of p75 is competent to induce cell death in a manner similar to the FasR. The FasR binds to homotrimeric or higher order oligomeric forms of the Fas ligand. Ligand-induced receptor aggregation leads to the association of the FasR death domain with downstream death effector molecules, which subsequently trigger cell death. ${ }^{28}$ In addition, an agonist antibody, Jo2, can trigger the same Fas-mediated death observed with the naturally occurring Fas ligand in immune cells. ${ }^{29}$

To determine whether the p75 cytoplasmic domain behaves in a way similar to the FasR intracellular domain, chimeric cDNAs which contain murine FasR extracellular sequences linked to the cytoplasmic domain of rat p75 were constructed. This strategy allowed the death domain of p75 to replace the FasR death domain and permitted receptor oligomerization of the p75 cytoplasmic domain by FasR agonists. Two different constructs were generated, A7, which contains the transmembrane and cytoplasmic sequences of $\mathrm{p75}$, and B9, which contains the cytoplasmic sequence of p75 and the transmembrane sequence of the FasR (Figure 1). Using these chimeric receptors, we investigated whether the p75 death domain is competent to induce cell death.

To verify and compare the expression levels of the $A 7$ and B9 chimeric receptors, the receptor cDNAs were transiently transfected into COS-1 cells. Immunofluorescence experiments with Jo2, an agonist antibody against the murine FasR, indicated that the two chimeras were

\section{FasR p75 FasR p75 chimeras}

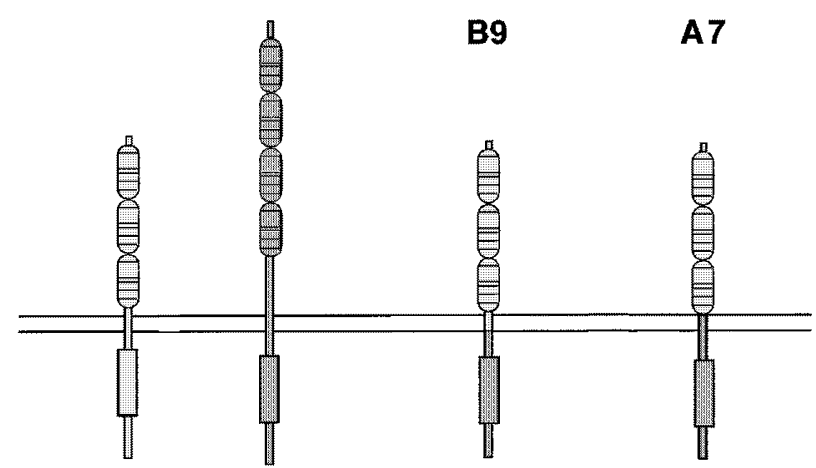

Figure 1 Schematic diagram of the FasR, p75 neurotrophin receptor, and chimeric receptors, A7 and B9. Each chimeric construct consists of the extracellular domain of the FasR fused to the intracellular domain of p75. A7 and $B 9$ differ in their transmembrane (TM) domains, with $A 7$ containing the p75 $\mathrm{TM}$ region and $\mathrm{B} 9$ containing the Fas $\mathrm{R}$ TM region. Construction of the $\mathrm{A} 7$ and $\mathrm{B} 9$ chimeric cDNAs by PCR is described in the Materials and Methods section expressed at the cell surface, at levels comparable to the wild-type FasR (Figure 2A). Cell lysates from COS-1 and 293 cells transfected with the Fas and p75 receptor constructs, along with A7 and B9 cDNAs, were also analyzed by Western blot analysis. Using an antibody made against the cytoplasmic domain of p75 (9992), chimeric receptors $A 7$ and $B 9$ were easily detected (Figure 2B). No immunoreactive proteins were detected in lysates from untransfected or wild-type FasR-transfected cells. As expected, the size of the chimeric receptors migrated at a smaller size than p75 due to the shorter extracellular domain of the FasR. A similar pattern of expression was detected in transfected 293 cells (Figure 2C).

Although each receptor was expressed at high levels in COS-1 cells, no evidence of apoptosis was observed, even in the presence of the Jo2 agonist antibody (data not shown), which is an effective inducer of Fas-mediated cell death. ${ }^{29}$ These observations suggest that COS-1 cells are refractory to apoptosis by FasR overexpression, unlike other cells such as U373, 293, MCF7, and Jurkat cells.

\section{U373 cells}

For recipient cells, we turned to U373 glioma and 293 cells, which are sensitive to Fas- and TNF-mediated cell killing. U373 cell death can be induced by treatment with human antiFas antibodies. ${ }^{30}$ These cells can be routinely transfected at an efficiency of $5 \%$. To assess the cell death activities of the chimeric receptors, we transiently transfected the receptor cDNAs together with pRC-lacZ into U373 cells. In the presence of the $\beta$-galactosidase substrate, $\mathrm{X}$-gal, we could quantitate transfected cells undergoing FasR-induced cell death. Within a few hours after transfection (3-6 h), FasRtransfected cells exhibited condensed nuclei by Hoechst 33342 staining, a hallmark of apoptosis (Figure 3).

Twenty-four hours following removal of the DNA precipitate, nearly $90 \%$ of FasR-transfected cells underwent cell death, as evidenced by the detachment of dying cells from the culture dish (Figure 4). The percentage of viable cells remaining on the dish would be calculated relative to sister cultures that were transfected with the empty vector and $\mathrm{pRC}$-lacZ. Cells transfected with the pcDNA3 vector or with pRC-lacZ alone displayed no changes in viability (Figure 4). Compared to vector controls, very few dying cells were observed after transfection of the wild-type p75 receptor or the A7 chimeric construct (data not shown). In contrast, 40-50\% of U373 cells expressing the B9 receptor, which contains the FasR transmembrane region, appeared morphologically similar to those cells undergoing Fas-mediated apoptosis. In addition to differences in the magnitude of cell death, the time course of FasR- and B9-induced killing differed in that FasR-expressing cells died within $\sim 6 \mathrm{~h}$ of receptor expression, while B9-expressing cells required $>24 \mathrm{~h}$ to die (data not shown).

Cell death mediated by p75 expression has been detected in several cell lines; ${ }^{15,16}$ however, these results were obtained under conditions in which serum was 
withdrawn from growing cells. Under normal growth conditions, expression of p75 receptors in many cell types, including U373 and 293 cells, does not activate death pathways ${ }^{9}$ (data not shown). The FasR initiates apoptosis through receptor oligomerization, and clustering of FasRs can be achieved through agonist antibodies or the Fas ligand. Therefore, we tested the effects of a murine Fas agonist antibody, Jo2, in transfected U373 cells to determine whether aggregation of these receptors enhances apoptosis.

Treatment of transfected U373 cells with the Jo2 antibody, however, did not alter the number of cells undergoing cell death following transfection (Figure 4).
Therefore, the killing activity of FasR and the B9 chimeric receptor in U373 cells appears to be independent of ligandinduced aggregation, presumably because the receptors are expressed at sufficiently high levels to function in the absence of ligand.

\section{3 cells}

A human embryonic kidney cell line, 293, was found to be sensitive to Fas-mediated apoptosis. ${ }^{31}$ To compare further the effects of the chimeric receptors, we transiently transfected 293 cells with the receptor cDNAs. Western blot analysis (Figure 2C) and indirect immunofluorescence

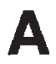

$\mathbf{U}$
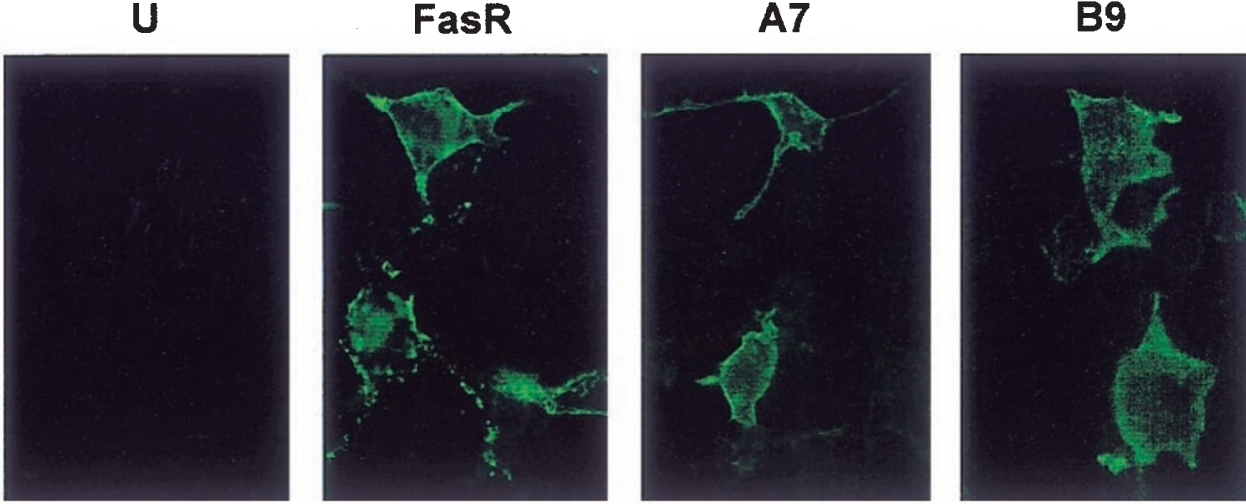

B

U p75 FasR A7 B9

$97.0 \mathrm{kDa}-$

$68.0 \mathrm{kDa}-$

45.0 kDa-
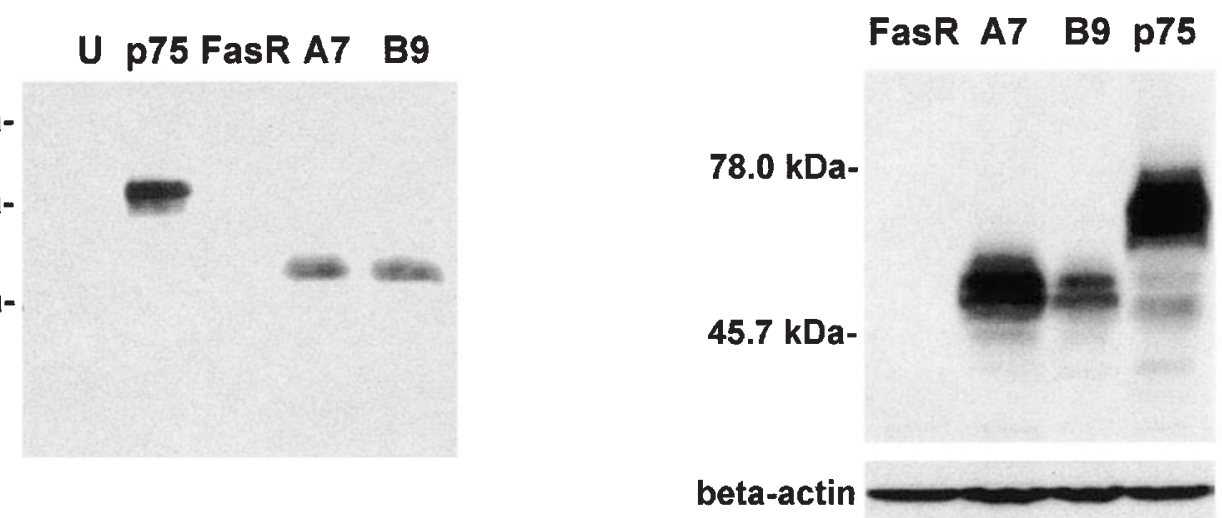

Figure 2 Expression of the Fas receptor (FasR), p75, and A7 and B9 chimeras. (A) Transfected COS-1 cells were subjected to indirect immunofluorescence with $\mathrm{J} 02$, an antibody that recognizes the extracellular domain of the murine Fas receptor. ${ }^{29}$ (B) Cell lysates prepared from COS-1 cells transiently transfected with FasR, p75, A7, and B9 constructs were immunoblotted with 9992, an antibody specific for the intracellular domain of p75. U=untransfected. (C) Cell lysates were prepared from 293 cell transiently transfected with FasR, p75, A7, and B9 expression constructs and then subjected to Western blot analysis with the anti-p75 antibody, 9992 


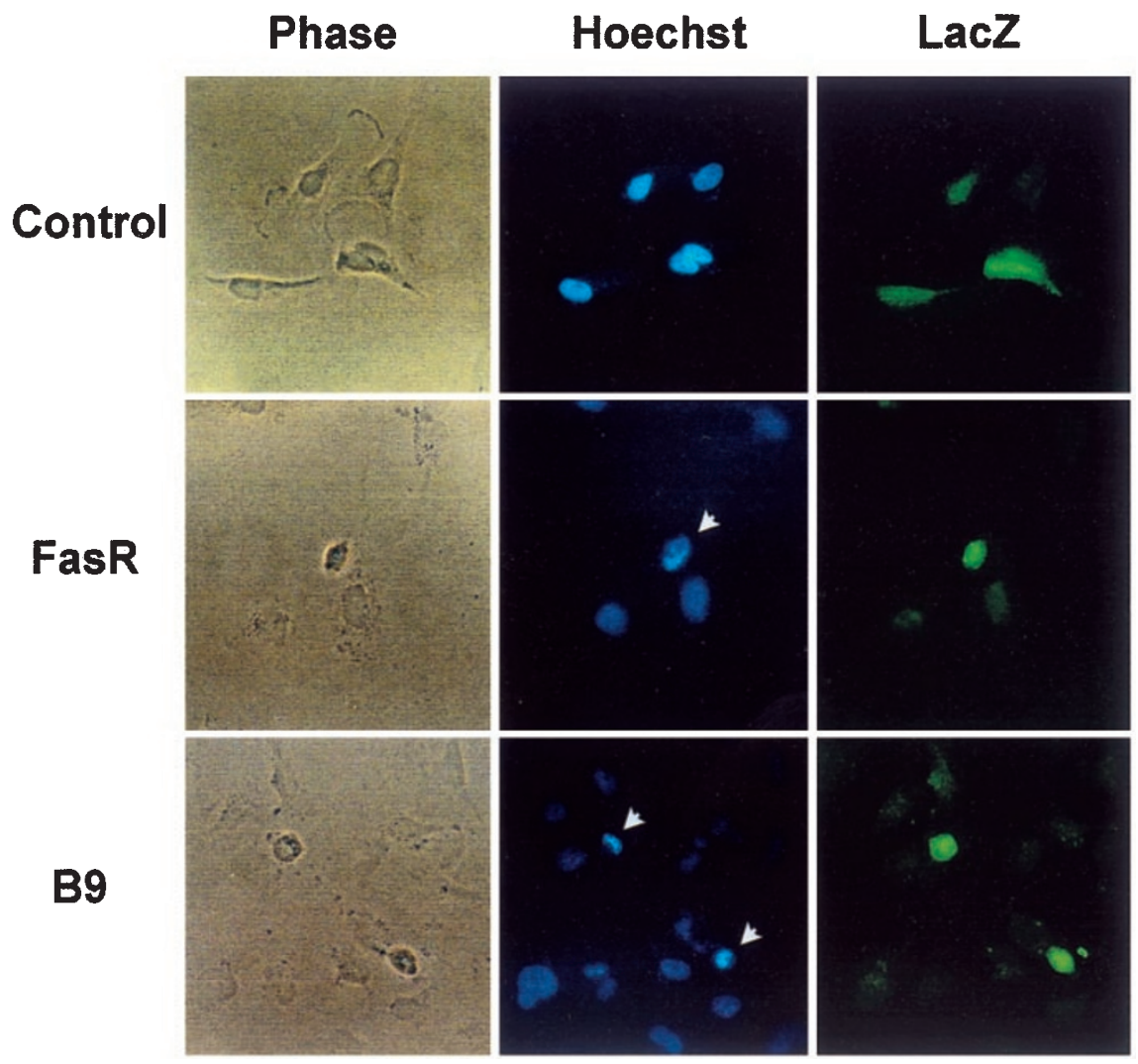

Figure 3 Morphology of U373 cells transiently transfected with the FasR and B9 chimeric receptor. After transfection, cells were plated into 24-well plates and processed for staining. Vector (pcDNA3) and receptor-transfected cells were identified with $\beta$-galactosidase antibody staining (LacZ column), and nuclei were examined by Hoechst 33342 staining (Hoechst column). Control=vector alone

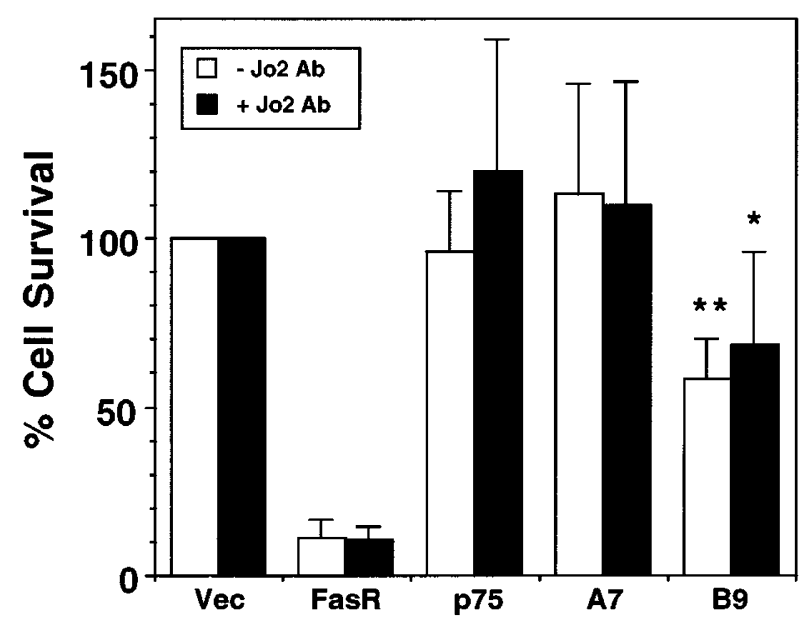

Figure 4 U373 cell viability following transient transfection with receptor constructs. Transfected cells were incubated for $36-48 \mathrm{~h}$ in serum-free medium in the absence or presence of $50 \mathrm{ng} / \mathrm{ml}$ anti-Fas Jo2 agonist antibody, after which cells were fixed and stained in the presence of X-gal, the $\beta$ galactosidase substrate. The number of viable blue cells were counted and calculated as a percentage of vector-transfected cells. All bars depict mean \pm S.E.M. from five independent experiments. ${ }^{* \star}$ Indicates a significant difference between untreated vector and untreated B9 at $P<0.002$, and *indicates a significant difference between treated vector and treated $B 9$ at $P<0.02$, both according to Student's $t$-test
(Figure 6) verified the expression of the transfected receptors. In addition, assessment of FasR, A7 and B9 cell surface expression by flow cytometry indicated that the different receptors were expressed at similar levels in a comparable percentage of transfected cells (Table 1). For these measurements, an antibody (Jo2) was used that detected cell surface expression of FasR and the chimeric constructs. The percentage of FasR-expressing cells was found to be slightly lower than that of the chimeraexpressing cells. Overall, no significant differences in expression level among the constructs was detected by Western blot or flow cytometry. Since the efficiency of transfection, $60-70 \%$, was considerably higher than in U373 cells, the 293 cell system was used to quantitate cell death.

As a first measure of cell death, Annexin $\mathrm{V}$ staining was performed on transfected 293 cultures. Annexin V is a naturally occurring protein which avidly binds to phosphatidylserine (PS). During the early stages of apoptosis, PS translocates from the inner to the outer leaflet of the plasma membrane, allowing detection by Annexin V. As a marker of transfection, a GFP construct was co-transfected with the receptor constructs. The percentage of Annexin $V$ - and GFP-double positive cells among GFP-positive cells for each condition was assessed by flow cytometry (Figure 5). 
Table 1 Assessment of FasR and chimeric receptor expression by flow cytometry

\begin{tabular}{lcc}
\hline Construct & $\begin{array}{c}\text { \% Jo2-positive } \\
\text { cells }\end{array}$ & $\begin{array}{c}\text { Mean } \\
\text { Jo2-fluorescence } \\
\text { (arbitrary FL2 units) }\end{array}$ \\
\hline FasR & 28.4 & 294.3 \\
A7 & 39.3 & 255.5 \\
B9 & 37.9 & 203.1 \\
\hline
\end{tabular}

Two hundred and ninety-three cells were transiently transfected for $24 \mathrm{~h}$ with the indicated receptor cDNAs. Afterwards, cells were resuspended in PBS containing $1 \%$ BSA and $0.05 \%$ sodium azide and incubated at $4^{\circ} \mathrm{C}$ for 30 min with $0.5 \mu \mathrm{g}$ anti-FasR Jo2 antibody (phycoerythrin (PE)-conjugate) per $10^{6}$ cells. For each condition, 5000 events were counted by flow cytometry. Mean Jo2-fluorescence represents the average intensity of Jo2-PE-fluorescence per event in the Jo2positive subpopulation. FL2 refers to the flow cytometry channel used to measure Jo2-PE fluorescence

Transfection with the FasR yielded low to moderate levels of cell death, 14.5 and $25.7 \%$, at 12 and $36 \mathrm{~h}$ posttransfection. In contrast, p75-transfected cells were not significantly different from vector-transfected cells at both time points. Expression of A7 and B9 chimeric receptors $12 \mathrm{~h}$ following transfection elicited very low levels of cell death, which did not increase at $36 \mathrm{~h}$.

To determine whether receptor oligomerization after ligand treatment would augment the effects of receptormediated cell death of 293 cells, FasR-, A7-, and B9transfected cells were treated with the Jo2 antibody. Also, p75-transfected cells were treated with NGF. At 12 and $36 \mathrm{~h}$ post-transfection, ligand treatment increased FasRmediated apoptosis by 92.9 and $61.2 \%$, respectively, compared to FasR transfection alone. NGF treatment of p75-transfected cells did not alter p75's inability to induce 293 cell death, even with increasing time. However, after transfection with the chimeric A7 and B9 receptors, Jo2 treatment resulted in a small increase in Annexin $\mathrm{V}$ staining at $12 \mathrm{~h}$ and a higher augmentation of staining at $36 \mathrm{~h}$. At $36 \mathrm{~h}$ post-transfection, Jo2 exposure increased A7-induced cytotoxicity 5.4-fold and B9-induced cytotoxicity 3.2-fold compared to untreated cells expressing the transfected receptors. These results are consistent with the results obtained in U373 cells, in that a low magnitude and slow time course of B9-induced killing was observed compared to FasR-mediated death.

As an independent measure of cell death and to confirm further the apoptotic nature of A7- and B9-mediated killing, TUNEL staining on 293 cells transfected with FasR, A7, and B9 constructs was performed. The TUNEL reaction labels free termini of fragmented DNA, which is indicative of the late stages of programmed cell death. Vectortransfected cells did not give rise to receptor expression $36 \mathrm{~h}$ after transfection, as detected by Jo2 immunofluorescence, or any TUNEL-positive cells (Figure 6). Vectortransfected cells treated for $36 \mathrm{~h}$ with Jo2 antibody similarly showed little or no evidence of TUNEL positivity (data not shown). On the other hand, FasR transfection yielded numerous TUNEL-positive cells that displayed simultaneous Jo2 staining $36 \mathrm{~h}$ following transfection, and the number of TUNEL-positive cells increased with Jo2 antibody treatment. Consistent with the Annexin $\mathrm{V}$ results,

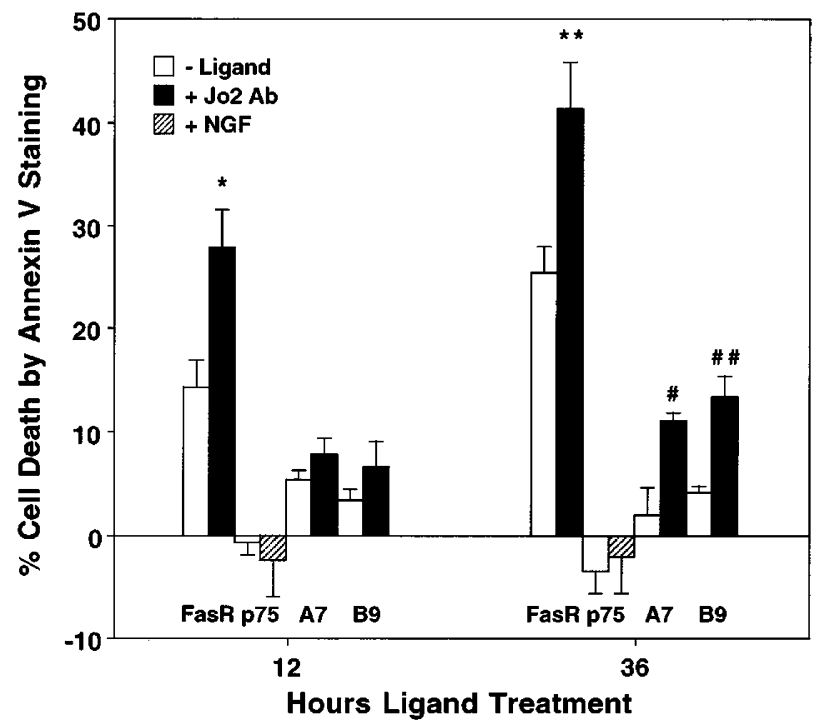

Figure 5 Cell death of 293 cells following transient transfection with receptor constructs as assessed by Annexin V-PE flow cytometry. After co-transfecting cells with a GFP construct and cDNAs encoding pcDNA3, FasR, p75, A7, or B9, cells were incubated in DMEM plus $5 \%$ FBS with or without ligand for 12 or $36 \mathrm{~h}$. FasR-, A7, and B9-transfected cells were exposed to the anti-Fas agonist antibody Jo2 $(500 \mathrm{ng} / \mathrm{ml})$ while p75-transfected cells were exposed to NGF $(100 \mathrm{ng} / \mathrm{ml})$. pcDNA3 cells were exposed for 12 or $36 \mathrm{~h}$ to DMEM plus $5 \%$ FBS with (1) no ligand, (2) Jo2 antibody, or (3) NGF. Following ligand exposure, cells were stained with Annexin V-PE and assessed by flow cytometry for the percentage of Annexin V- and GFP-double positive cells among total GFPpositive cells. To assess receptor-specific cell death, Annexin $V$ percentages obtained under the different pcDNA3-transfected conditions were subtracted from the values measured under receptor-transfected conditions with corresponding ligand and time conditions. Final Annexin V-positive percentages were expressed as (condition-control)/(100-control). All bars represent mean \pm S.E.M. from three independent experiments. * and ** indicate significant differences between FasR and FasR+Jo2 at 12 and $36 \mathrm{~h}$ respectively $(P<0.03)$. \#Indicates a significant difference between $A 7$ and $\mathrm{A} 7+\mathrm{J} 02$ at $36 \mathrm{~h}(P<0.03)$. \#\#Indicates a significant difference between B9 and $\mathrm{B} 9+\mathrm{J} 02$ at $36 \mathrm{~h}(P<0.006)$. Statistical analysis was performed by Student's $t$ test

A7 and B9 transfection resulted in few TUNEL- and Jo2double positive cells $36 \mathrm{~h}$ post-transfection. As with the FasR, Jo2 antibody treatment potentiated both A7- and B9mediated cell death.

Using GFP as marker for co-transfection, the percentage of TUNEL- and GFP-double positive cells among total GFPpositive cells for each receptor transfection was determined after a $36 \mathrm{~h}$ incubation, with or without Jo2 antibody treatment (Figure 7). Exposure to the Jo2 antibody potentiated the apoptosis induced by FasR transfection by 1.78-fold. The response of A7- and B9-induced apoptosis was considerably lower but was enhanced by exposure to Jo2. Taken together, these results indicate that engagement of FasR by Jo2 induced a greater level of apoptosis, compared to the A7 and B9 chimeric constructs that contain the p75 cytoplasmic domain. Nevertheless, we did observe an increase in chimera-induced cell death with agonist antibody compared to receptor transfection alone, suggesting that a small apoptotic effect could be mediated by aggregation of the p75 cytoplasmic domain. 

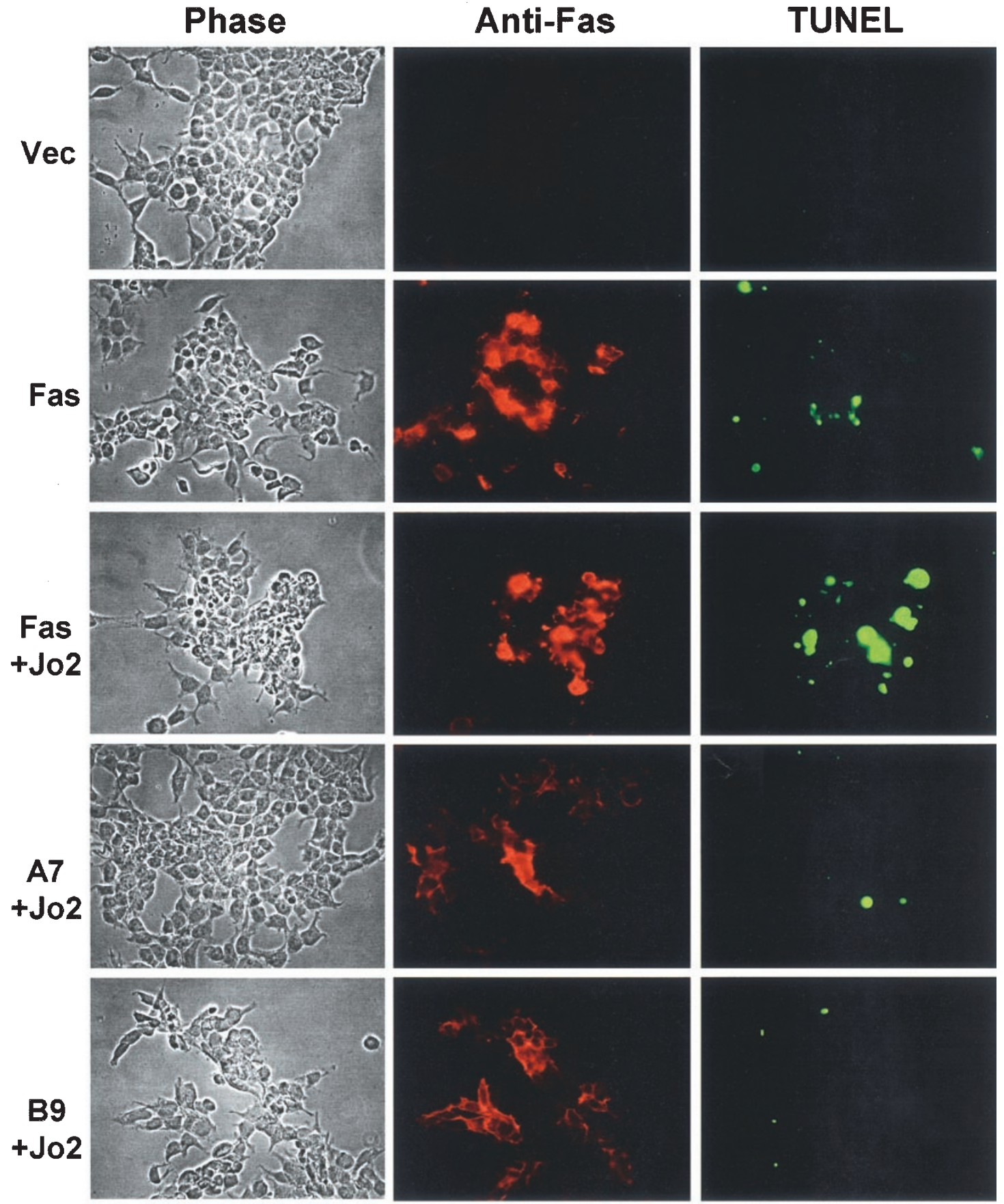

Figure 6 Phase-contrast microscopy, immunostaining, and TUNEL assays of transiently transfected 293 cells. Following 1 day transfection with pcDNA3 vector, FasR, A7, and B9 constructs, cells were exposed for $36 \mathrm{~h}$ to DMEM plus $5 \%$ FBS with or without $500 \mathrm{ng} / \mathrm{ml} \mathrm{Jo2}$ antibody. Cells were then subjected to both anti-Fas Jo2 immunofluorescence (second column) and TUNEL staining (third column). Vec=vector

\section{Discussion}

Structural analysis of the C-terminal 80 amino acid sequence of the p75 receptor reveals features similar to the death domain of the FasR ${ }^{26,27}$ However, the results here indicate that the abilities of these two receptors to induce cell death in U373 cells are markedly different. A comparison of cell death activities of p75 and the FasR indicates that expression of the
FasR intracellular region results in much greater cell death than expression of the p75 intracellular region. These results were further supported in transfected 293 cells. Transfection of FasR resulted in apoptosis, as measured by Annexin V staining and TUNEL reactivity, whereas introduction of p75 did not alter cell viability. A clear effect of the agonist antibody, Jo2, could be observed after treatment of FasR- compared to vector-transfected cells but not with 293 cells overexpressing 


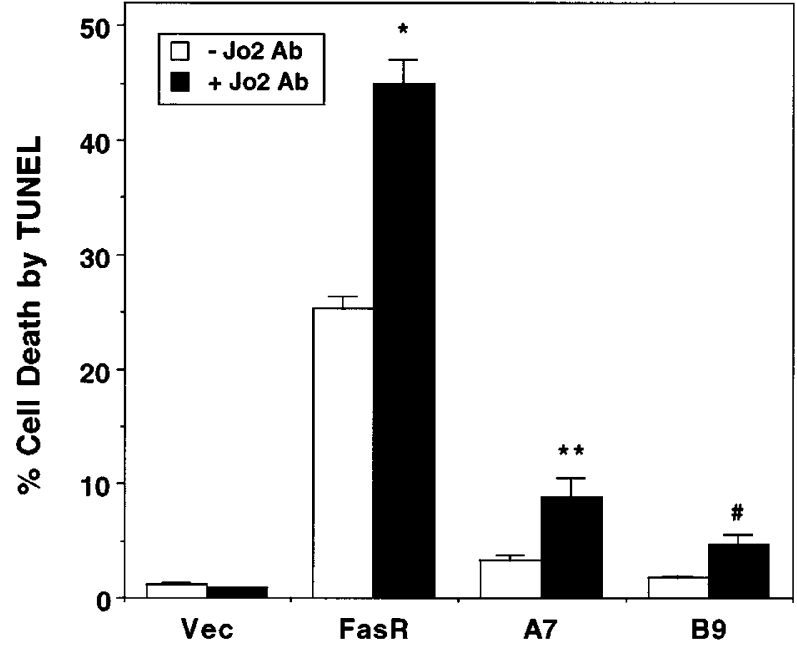

Figure 7 Quantitation of TUNEL-positive 293 cells following transient transfection with receptor constructs. Cells were co-transfected for 1 day with a GFP construct and one of the following cDNAs: pcDNA3 vector, FasR, A7 or B9. Afterwards, cells were incubated for $36 \mathrm{~h}$ in DMEM plus $5 \% \mathrm{FBS}$ with or without $500 \mathrm{ng} / \mathrm{ml} \mathrm{Jo2}$ antibody, processed for TUNEL staining, and counted. Per cent TUNEL-positive cells represents the number of TUNEL- and GFP-double positive cells divided by the number of GFP-positive cells. All bars represent mean + S.E.M. from three to four independent experiments. ${ }^{*}$ Indicates significant difference between FasR and FasR+Jo2 at $P<0.001$. ${ }^{* *}$ Indicates significant difference between $A 7$ and $A 7+J 02$ at $P<0.04$. \#Indicates significant difference between $\mathrm{B} 9$ and $\mathrm{B} 9+\mathrm{J} 02$ at $P<0.01$. Statistical analysis was performed by Student's $t$-test. $\mathrm{Vec}=\mathrm{vector}$

p75. A similar ligand enhancement of cell death was observed in 293 cells transfected with the chimeras, although to a diminished degree compared to ligand enhancement in FasRtransfected cells.

We infer from these experimental results that the mechanism of p75 killing is different from that of FasR. Several features may contribute to the differences between p75 and FasR. For example, the TNF and Fas receptor death domains easily self-aggregate, ${ }^{32}$ whereas selfassociation has not been observed with the death domain of p75 (unpublished results). This may be due to amino acid sequence differences or to slight alterations in structure. For example, the first $\alpha$-helix of the death domain is oriented in different positions for the Fas and p75 receptors. Also, the death domain of p75 resembles a death effector domain structure ${ }^{33}$ raising the possibility that protein-protein interactions relevant to cell death are mediated by this domain.

In the TNF receptor superfamily, receptor activation occurs via clustering, which is mediated by binding of multimeric ligands. ${ }^{34}$ Following oligomerization, the FasR recruits the adaptor molecule FADD/MORT1 via its death domain, which, in turn, leads to the recruitment and activation of the caspase proteases FLICE/MACH/caspase-8 and FLICE-2/caspase-10. These enzymes then cleave other caspases to initiate the apoptotic signal transduction pathway. ${ }^{35,36}$ The p55 TNF receptor also uses this pathway, recruiting FADD/MORT1 via the adaptor protein TRADD. ${ }^{37-39}$ Thus far, cleavage of FLICE/MORT1/caspase-8 has not been observed in oligodendrocytes undergoing p75-dependent apoptosis. ${ }^{40}$ Neither is there evidence that FADD binds directly to $p 75 .^{41}$

The p75 receptor can participate in the initiation or potentiation of the apoptotic process, ${ }^{11,14-18}$ but the components responsible for signaling remain to be identified. Cell death mediated by p75 is not a general phenomenon but instead requires specific conditions, with regard to cell type, cell cycle stage, and developmental stage. Although there are examples in which p75 has been directly shown to be responsible for apoptotic cell death, it is also apparent that many cell types express p75 but do not undergo apoptosis. This suggests that cellular context and history are important determinants and that p75 alone is not sufficient for this pro-death activity. The pro-apoptotic effect of p75 may be influenced by age in culture, metabolic impairment, hypoxia, or other types of 'stress' signals, such as nerve injury or inflammation. In this respect, the cell death properties of this receptor may reflect its proposed function as a cytokine or stress receptor. ${ }^{40}$

Several mechanisms have been proposed to explain the actions of $p 75$. The p75 receptor may act as an apoptotic receptor in the absence of ligand. ${ }^{6,15,17,42}$ This hypothesis has been partially derived from experiments in which cell death is induced by either serum or NGF withdrawal. In this model, NGF acts to stop cell death by directly binding p75. These conditions may trigger changes in the structure or localization of p75 or in the protein substrates that interact with p75. Alternatively, this ligand-independent activity of p75 may be explained by recruitment of cellular death proteins under conditions of overexpression.

A ligand-dependent mechanism for cell death has been observed in vitro and in vivo for the p75 receptor, in which antibodies against NGF block apoptotic cell death, or NGF binding to p75 directly leads to cell death. ${ }^{11,14}$ This leads to two diametrically opposed killing mechanisms involving NGF and p75, ligand-dependent and ligand-independent. Both of these mechanisms can be reconciled by the data presented in this study, if proapoptotic cellular proteins can interact with the p75 receptor and transduce competent signals in the absence of ligand. A prediction from the results derived by TNF receptor family members is that trimerization or higher order aggregation of p75 may be more effective in killing cells than dimerization, as is normally induced by the neurotrophins.

Mechanisms to explain p75 function have largely been extrapolated from the actions of the TNF receptor family members. The p75 receptor can activate ceramide production, $\mathrm{NF}-\kappa \mathrm{B}$, and $\mathrm{JNK},{ }^{7,43}$ depending upon the cell type and history. Although it is premature to define a complete biochemical pathway initiated by NGF binding to p75, it is plausible to make certain predictions on potential signaling candidates given the structural resemblance of p75 to the TNF receptor superfamily. The cytoplasmic region of p75 may serve as a module for recruiting cell death proteins, such as caspases. The structural data would predict that p75 may interact with common adaptor proteins, such as the TRAF family members, or other proteins similar to TRADD and FADD. Indeed, TRAF6 has been shown to be recruited to the p75 receptor upon treatment with neurotrophins and mediates p75-dependent 
NF- $\kappa$ B activation in cultured Schwann cells. ${ }^{44}$ Additionally, catalytically inactive caspases such as I-FLICE/CASH may provide a means for blocking cell death by binding to p75, as has been shown with TNF and Fas receptors. ${ }^{45,46}$

Although the death domain of p75 may associate with proteins that interact with other TNF receptor family members, the mechanisms of membrane recruitment may differ significantly for p75 compared to other TNF receptor family members. For instance, in primary DRG cultures maintained with LIF, p75 may transduce its death-inducing signals via its juxtamembrane region rather than its death domain. ${ }^{41}$ Testing these and other signaling mechanisms will reveal how the p75 neurotrophin receptor differs from other TNF receptor members in promoting cell death.

\section{Materials and Methods}

\section{Construction of FasR/p75 chimeras}

A hybrid PCR-based strategy was used to construct two chimeras consisting of the extracellular domain of the mouse FasR and the intracellular domain of the rat p75 receptor. Chimera A7 cDNA encodes the extracellular portion of the FasR fused to the transmembrane and intracellular segments of p75, whereas chimera $\mathrm{B} 9$ consists of the extracellular and transmembrane portions of $\mathrm{mFasR}$ fused to the intracellular domain of p75NTR (Figure 1). The primers used in the construction of the chimeras were as follows. Primer I, $5^{\prime}$ ATTTGCGGCCGCCCACCATGCTGTGGATCTGGGC-3'; primer II, 5'AGGAATGAGGCGATTTCTGGGACTTTG-3'; primer III, 5' AGAAATCGCCTCATTCCTGTCTATTGCTC-3'; primer IV, 5'-TGAGGCAGTCTGCGTATGGGTC-3'; primer $\mathbf{v}, 5^{\prime}$-CCACCTCTTATATATAAATACAAGTGGAATTAAC-3'; primer VI, $5^{\prime}$ TTTATATATAAGAGGTGGAACAGCTGC-3'. Using pCDNA3-mFasR as the template in parallel reactions, the primer pair I and $V$ and the primer pair I and II were used to amplify the extracellular portion of FasR with and without the FasR transmembrane domain, respectively. Likewise, with pBluescript-p75 as the template in parallel reactions, primer pair III and IV and primer pair IV and VI were used to amplify the intracellular portion of p75 with and without the p75 transmembrane domain, respectively. The PCR conditions used for the above reactions were as follows: $1 \mathrm{~min}$ at $94^{\circ} \mathrm{C}, 1 \mathrm{~min}$ at $48^{\circ} \mathrm{C}$, and $1 \mathrm{~min}$ at $72^{\circ} \mathrm{C}$ for ten cycles; $1 \mathrm{~min}$ at $94^{\circ} \mathrm{C}, 1 \mathrm{~min}$ at $55^{\circ} \mathrm{C}$, and $1 \mathrm{~min}$ at $72^{\circ} \mathrm{C}$ for 20 cycles; $10 \mathrm{~min}$ at $72^{\circ} \mathrm{C}$. The overlapping products of the primer I/ II and primer III/IV amplifications were combined, denatured, annealed, and extended with Klenow in the presence of $250 \mu \mathrm{M}$ dNTPs to yield template $A$. The I/V and VI/IV PCR products were treated in the same manner to yield template $\mathbf{B}$. Finally, in a second set of PCRs, primers I and IV were used with templates $\mathbf{A}$ and $\mathbf{B}$ in separate reactions. The PCR conditions used for this second set of reactions were as follows: $1 \mathrm{~min}$ at $94^{\circ} \mathrm{C}, 1 \mathrm{~min}$ at $58^{\circ} \mathrm{C}$, and $1 \mathrm{~min}$ at $72^{\circ} \mathrm{C}$ for 25 cycles followed by $10 \mathrm{~min}$ at $72^{\circ} \mathrm{C}$. These products were digested with Notl and Kasl and ligated into the corresponding sites of pcDNA3-p75 to give the final chimeric expression constructs, A7 and B9. Both constructs were verified by automated DNA sequencing (Rockefeller University DNA sequencing facility).

\section{Cell culture and transfection}

COS- 1 cells, 293 cells, and the glioblastoma-derived cell line U373 were cultured at $37 \%$ in $5 \% \mathrm{CO}_{2}$ in Dulbecco's modified Eagle's medium (DMEM) containing $10 \%$ fetal bovine serum and penicillin/ streptomycin (GIBCO BRL). For transient transfection of COS-1 and U373 cells, cells were cultured in $35 \mathrm{~mm}$ dishes and transfected with

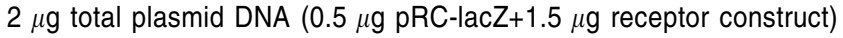
using Lipofectamine (Gibco BRL) for U373 cells and the calcium phosphate method for COS-1 cells. Two hours post-transfection with Lipofectamine, U373 cells were split and allowed to recover in serumcontaining medium for $12-24 \mathrm{~h}$. COS-1 cells were split 12-24 h posttransfection. For transient transfection of 293 cells, cells plated in 6well plates $\left(1.3 \times 10^{6}\right.$ cells/plate) were transfected for $24 \mathrm{~h}$ with $0.75 \mu \mathrm{g}$ receptor construct and, for indicated experiments, cotransfected with $0.1 \mu \mathrm{g}$ GFP construct using Fugene 6 (Roche).

\section{Western blot analysis}

To verify protein expression of the chimeras, cos- 1 cells, a line unresponsive to Fas-induced killing, and 293 cells were used. COS-1 cells were plated in $10 \mathrm{~cm}$ dishes and transiently transfected with $20 \mu \mathrm{g}$ of plasmid DNA. Cells (293) were cultured in 6-well plates and transiently transfected with $2 \mu \mathrm{g}$ plasmid DNA per well. Cells were lysed in $0.2-0.5 \mathrm{ml}$ Nonidet P-40 lysis buffer ( $1 \%$ Nonidet $\mathrm{P}-40$, $20 \mathrm{mM}$ Tris $\mathrm{pH} 8.0,200 \mathrm{mM} \mathrm{NaCl}, 1 \mathrm{mM}$ EDTA, $2 \mu \mathrm{g} / \mathrm{ml}$ aprotinin, $1 \mu \mathrm{g} / \mathrm{ml}$ leupeptin, and $25 \mu \mathrm{g} / \mathrm{ml}$ phenylmethylsulfonyl fluoride). Protein lysates were resolved on a $10 \%$ SDS-polyacrylamide gel under reducing conditions and transferred to PVDF membrane. The membrane was washed with $1 \times$ TBS-T (10 mM Tris pH 8.0, $100 \mathrm{mM}$ $\mathrm{NaCl}, 1 \mathrm{mM}$ EDTA, and $0.1 \%$ Tween-20), blocked with $5 \%$ milk, incubated in 1\% milk/TBS-T containing a 1:5000 dilution of the antip75 antibody 9992 for $1 \mathrm{~h}$ at room temperature, washed three times in TBS-T, and incubated for $1 \mathrm{~h}$ at room temperature in 1\% milk/TBS-T with anti-rabbit secondary antibody conjugated to HRP (Roche). Protein was visualized by ECL (Amersham) and exposure to X-ray film.

\section{Flow cytometry}

Receptor expression was followed by flow cytometry after transfection in 293 cells. The FasR, A7, and B9 cDNAs $(0.75 \mathrm{mg})$ were introduced into 293 cells plated in 6-well plates by Fugene 6-mediated transfection. Cells were suspended in PBS-EDTA (1 mM) and washed twice with PBS containing $1 \%$ BSA and $0.05 \%$ sodium azide. After incubating cells in $0.5 \mathrm{mg}$ per $10^{6}$ cells Jo2 antibody phycoerythrin (PE)-conjugate (Pharmingen), cells were washed twice and subjected to flow cytometry for Jo2-PE fluorescence.

\section{Immunocytochemistry}

For cell surface detection of Fas receptor, A7, and B9, COS-1 cells plated in $10 \mathrm{~cm}$ dishes were transfected with $20 \mu \mathrm{g}$ plasmid DNA, split into 24-well plates, allowed to recover, and processed for staining as follows. Cells were fixed in $4 \%$ paraformaldehyde and incubated in PBS containing $1 \%$ normal goat serum (NGS) and $2 \mu \mathrm{g} / \mathrm{ml}$ anti-Fas Jo2 antibody (Pharmingen). A goat anti-hamster secondary antibody conjugated to FITC (Vector) was used for detection.

For simultaneous TUNEL-labeling and plasma membrane detection of receptors in 293 cells, cells were plated on 4-chamber plastic slides, transfected with $0.75 \mu \mathrm{g}$ plasmid DNA, and stained after $36 \mathrm{~h}$. Cells were first fixed in $4 \%$ paraformaldehyde, permeabilized in $0.1 \%$ Triton X-100 for 2 min, and blocked in PBS containing 10\% NGS for $1 \mathrm{~h}$. Cells were then incubated in PBS containing $1 \%$ NGS and $2 \mu \mathrm{g} / \mathrm{ml}$ Jo2 antibody and incubated in TUNEL-FITC reaction solution (Roche) for $1 \mathrm{~h}$ at $37^{\circ} \mathrm{C}$. Receptor expression was visualized by 
incubation in PBS with 1\% NGS and anti-rabbit secondary antibody conjugated to Texas Red (Jackson Immunoresearch).

For detection of $\beta$-galactosidase-positive cells, transfected U373 cells were fixed in $4 \%$ paraformaldehyde, permeabilized with $0.1 \%$ Triton X-100, blocked in $1 \%$ NGS, incubated with a rabbit $\beta$ galactosidase antibody $\left(5^{\prime}-3^{\prime}\right.$, Boulder CO, USA), and incubated with a biotinylated goat anti-rabbit secondary antibody and FITCconjugated streptavidin. For Hoechst 33342 staining, U373 cells were incubated for $10 \mathrm{~min}$ at $37^{\circ} \mathrm{C}$ in Hoechst 33342 solution (Molecular Probes) at a 1:10000 dilution.

\section{Cell death assays}

For assessment of U373 cell death, cells were incubated for various times in serum-free medium $\pm 50 \mathrm{ng} / \mathrm{ml}$ anti-Fas Jo2 agonist antibody, after which cells were fixed in $4 \%$ paraformaldehyde and incubated in potassium ferrocyanide/potassium ferrous cyanide containing $1 \mathrm{mg} / \mathrm{ml}$ $\mathrm{X}$-gal. The number of blue cells were counted and calculated as a percentage of vector-transfected control cells. Since dying cells detach from the cell culture dish, the remaining blue cells correspond to the number of viable transfected cells.

For Annexin V staining, 293 cells plated in 6-well plates were cotransfected with $0.1 \mu \mathrm{g}$ GFP construct and $0.75 \mu \mathrm{g}$ receptor construct for $24 \mathrm{~h}$ and exposed to no ligand, $500 \mathrm{ng} / \mathrm{ml}$ anti-Fas Jo2 agonist antibody, or $100 \mathrm{ng} / \mathrm{ml} \mathrm{NGF} \mathrm{(Harlan)} \mathrm{for} 12$ or $36 \mathrm{~h}$. Cells were suspended using Hank's balanced salt solution (HBSS) containing trypsin-EDTA and transferred into 96-well V-bottom plates. After washing cells twice with PBS plus $1 \%$ BSA, cells were incubated for 15 min in Annexin V conjugated to phycoerythrin (Pharmingen) in the dark at room temperature and washed once with PBS plus $1 \%$ BSA. To assess the percentage of Annexin V-/GFP-double positive cells among GFP-positive cells, 2000 events were counted per condition by flow cytometry.

For quantitation of TUNEL labeling, 293 cells plated in 6-well plates were transfected as described for Annexin $\mathrm{V}$ staining and then exposed to no ligand or $500 \mathrm{ng} / \mathrm{ml} \mathrm{Jo} 2$ antibody for $36 \mathrm{~h}$. Cells were suspended with HBSS containing trypsin-EDTA and transferred to 96 well V-bottom plates. Cells were then fixed in $4 \%$ paraformaldehyde, permeabilized in $0.1 \%$ Triton $\mathrm{X}-100$ for $2 \mathrm{~min}$, and incubated in TUNEL-TMR Red reaction solution (Roche) for $1 \mathrm{~h}$ at $37^{\circ} \mathrm{C}$. After two washes with PBS plus $1 \%$ BSA, cells were transferred into flat-bottom 96-well plates for counting by fluorescence microscopy. For each condition, 100 GFP-positive cells were counted and assessed for simultaneous positive TUNEL reactivity.

\section{Acknowledgements}

This work was supported by grants provided by the $\mathrm{NIH}$ (H Kong, AH Kim and MV Chao) and a fellowship from the Tri-Institutional MD/PhD program and the Life and Health Insurance Medical Research Fund (JR Orlinick).

\section{References}

1. Smith CA, Farrah T and Goodwin RG (1994) The TNF receptor superfamily of cellular and viral proteins: activation, costimulation, and death. Cell 76:959-962

2. Itoh N and Nagata S (1993) A novel protein domain required for apoptosis. Mutational analysis of human Fas antigen. J. Biol. Chem. 268: 10932-10937

3. Tartaglia LA, Ayres TM, Wong GHW and Goeddel DV (1993) A novel domain within the $55 \mathrm{kd}$ TNF receptor signals cell death. Cell 73: 213-216

4. Feinstein E, Kimchi A, Wallach D, Boldin M and Varfolomeev E (1995) The death domain: a module shared by proteins with diverse cellular functions. TIBS 20: $342-344$
5. Hofmann K and Tschopp J (1995) The death domain motif found in Fas (Apo-1) and TNF receptor is present in proteins involved in apoptosis and axonal guidance. FEBS Letters 371: $321-323$

6. Bredesen DE and Rabizadeh S (1997) p75NTR and apoptosis: Trk-dependent and Trk- independent effects. TINS 20: 287-291

7. Carter BD and Lewin GR (1997) Neurotrophins live or let die: Does p75NTR decide? Neuron 18: $187-190$

8. Dechant $\mathrm{G}$ and Barde $Y-A$ (1997) Signaling through the neurotrophin receptor p75 ${ }^{\text {NTR }}$. Curr. Opin. Neurobiol. 7: 413-418

9. Casaccia-Bonnefil P, Kong H and Chao MV (1998) Neurotrophins: the biological paradox of survival factors eliciting apoptosis. Cell Death \& Differ. 5: 357-364

10. Frade JM and Barde Y-A (1998) Nerve growth factor: two receptors, multiple functions. BioEssays 20: 137-145

11. Frade JM, Rodriguez-Tebar A and Barde Y-A (1996) Induction of cell death by endogenous nerve growth factor through its $p 75$ receptor. Nature 383: $166-168$

12. Frade JM and Barde $\mathrm{Y}-\mathrm{A}$ (1998) Microglia-derived nerve growth factor causes cell death in the developing retina. Neuron 20: 35-41

13. Majdan M, Lachance C, Gloster A, Aloyz R, Zeindler C, Bamji S, Bhakar A, Belliveau D, Fawcett J, Miller FD and Barker PA (1997) Transgenic mice expressing the intracellular domain of the p75 neurotrophin receptor undergo neuronal apoptosis. J Neurosci 17: 6988-6998

14. Casaccia-Bonnefil P, Carter BD, Dobrowsky RT and Chao MV (1996) Death of oligodendrocytes mediated by the interaction of nerve growth factor with its receptor p75. Nature 383: 716-719

15. Rabizadeh S, Oh J, Zhong LT, Yang J, Bitler CM, Butcher LL and Bredesen DE (1993) Induction of apoptosis by the low-affinity NGF receptor. Science 261 : $345-348$

16. Barrett GL and Georgiou A (1996) The low affinity nerve growth factor receptor p75 mediates death of PC12 cells after nerve growth factor withdrawal. J. Neurosci. Res. 45: 117-128

17. Barrett GL and Bartlett PF (1994) The p75 receptor mediates survival or death depending on the stage of sensory neuron development. Proc Natl Acad SciUSA 91: $6501-6505$

18. Bamji S, Majdan M, PozniakCD, Belliveau DJ, AloyzRJK, Causing CG and Miller FD (1998) The p75 neutotrophin receptor mediates neuronal apoptosis and is essential for naturally occurring sympathetic neuron death. J. Cell. Biol. 140: $911-923$

19. Soilu-Hanninen M, Ekert $P$, Bucci T, Syroid D, Bartlett $P$ and Kilpatrick T (1999) Nerve growth factor signaling through p75 induces apoptosis in Schwann cells via a bcl-2-independent pathway. J. Neurosci. 19: 4828-4838

20. Roux P, Colicos M, Barker P and Kennedy T (1999) p75 neurotrophin receptor expression is induced in apoptotic neurons after seizure. J. Neurosci. 19:68876896

21. Chao MV (1992) Neurotrophin receptors-a window into neuronal differentiation. Neuron. 9: 583-593

22. Benedetti M, Levi A and Chao MV (1993) Differential expression of nerve growth factor receptors leads to altered binding affinity and neurotrophin responsiveness. Proc. Natl. Acad. Sci. USA 90: 7859-7863

23. Barker PA and Shooter EM (1994) Disruption of NGF binding to the low-affinity neurotrophin receptor $\mathrm{p} 75$ reduces NGF binding to trkA on PC12 cells. Neuron 12: $203-215$

24. Verdi JM, Birren SJ, Ibanez CF, Persson H, Kaplan DR, Benedetti M, Chao MV and Anderson DJ (1994) p75(LNGFR) regulates trk signal transduction and NGF-induced neuronal differentiation in MAH cells. Neuron 12: 733-745

25. Yoon SO, Carter BD, Casaccia-Bonnefil P and Chao MV (1998) Competitive signaling between TrkA and p75 nerve growth factor receptors determines cell survival. J. Neuroscience. 18: 3273-3281

26. Liepinsh E, llag LL, Otting G and Ibanez CF (1997) NMR structure of the death domain of the p75 neurotrophin receptor. EMBO J. 16: 4999-5005

27. Huang BH, Eberstadt M, OlejniczakET, Meadows RP and Fesik SW (1996) NMR structure and mutagenesis of the Fas (Apo-1/CD95) death domain. Nature 384: $638-641$

28. Nagata S (1997) Apoptosis by death factor. Cell 85: 355-365

29. Ogasawara J, Watanabe-Fukunaga R, Adachi M, Matsuzawa A, Kasugai T, Kitamura Y, Itoh N, Suda T and Nagata S (1993) Lethal effect of the anti-Fas antibody in mice. Nature 364: 806-809

30. Wong GHW and Goeddel DV (1993) Fas antigen and p55 TNF receptor signal apoptosis through distinct pathways. J. Immunol. 152: 1751-1755 
31. Orlinick JR, Elkon K and Chao MV (1997) Separate domains of the human Fas ligand dictate self-association and receptor binding. J. Biol. Chem. 272:32221 32229

32. Boldin MP, Mett IL, Varfolomeev EE, Churnakov I, Shemer-Avni Y, Camonis JH, Wallach D (1995) Self association of the "death domains" of the p55 tumor necrosis factor (TNF) receptor and Fas/Apo1 prompts signaling for TNF and Fas/ Apo1 effects. J. Biol. Chem. 270: 387-391

33. Eberstadt M, Huang B, Chen Z, Meadows RP, Ng S-C, Zheng L, Lenardo MJ and Fesik SW (1998) NMR structure and mutagenesis of the FADD (Mort1) deatheffector domain. Nature 392: $941-945$

34. Ashkenazi A and Dixit VM (1998) Death receptors: signaling and modulation. Science 281: 1305-1308

35. Boldin MP, Goncharov TM, Goltsev YV and Wallach D (1996) Involvement of $\mathrm{MACH}$, a novel MORT1/FADD-interacting protease, in Fas/APO-1- and TNFinduced cell death. Cell 85: 803-815

36. Muzio M, Chinnaiyan AM, Fischkel FC, O'Rourke K, Shevchenko A, Ni J, Scaffid C, Bretz JD, Zhang M, Gentz R, Mann M, Krammer PH, Peter ME and Dixit VM (1996) FLICE, a novel FADD-homologous ICE/CED-3-like protease, is recruited to the CD95 (Fas/APO-1) death-inducing signaling complex. Cell 85: 817-827

37. Hsu H, Xiong J and Goeddel DV (1995) The TNF receptor 1- associated protein TRADD interacts with the death domain of Fas and initiates apoptosis. Cell 81: 495-504

38. Hsu H, Shu H-B, Pan M-P and Goeddel DV (1996) TRADD-TRAF2 and TRADDFADD interactions define two distinct TNF receptor-1 signal transduction pathways. Cell 84: 299-308
39. Chinnaiyan AM, Tepper CG, Seldin MF, O'Rourke K, Kischkel FC, Hellbardt S, Krammer PH, Peter ME and Dixit VE (1996) FADD/MORT1 is a common mediator of CD95 (Fas/APO-1) and tumor necrosis factor receptor-induced apoptosis. J. Biol. Chem. 271: 4961-4965

40. Gu C, Casaccia-Bonnefil P, Srinivasan A and Chao MV (1999) Oligodendrocyte cell death mediated by caspase activation. J. Neuroscience 19: 3043-3049

41. Coulson EJ, Reid K, Barrett GL and BartlettP (1999) p75 neurotrophin receptormediated neuronal death is promoted by $\mathrm{Bcl}-2$ and prevented by Bcl-xL. J. Biol. Chem. 274: 16387-16391

42. Cortazzo MH, Kassis ES, Sproul KA, Schor NF (1996) Nerve growth factor (NGF)-mediated protection of neural crest cells from antimitotic agent-induced apoptosis: The role of the low-affinity NGF receptor. J. Neurosci. 16:3895-3899

43. Bothwell M (1996) p75NTR: A receptor after all. Science 272: 506-507

44. Khursigara G, Orlinick JR and Chao MV (1999) Association of TRAF6 with the p75 neurotrophin receptor. J. Biol. Chem. 274: 2597-2600

45. Hu S, Vincenz C, Ni J, Gentz R and Dixit VM (1997) I-FLICE, a novel inhibitor of tumor necrosis factor receptor-1 and CD95-induced apoptosis. J. Biol. Chem. 272: $17255-17257$

46. Goltsev YV, Kovalenko AV, Arnold E, Varfolomeev EE, Brodianski VM and Wallach D (1997) CASH, a novel caspase homologue with death effector domains. J. Biol. Chem. 272: 19641-19644 